\title{
Matched comparison of corneal higher order aberrations induced by SMILE to femtosecond assisted LASIK and to PRK in correcting moderate and high myopia: $3.00 \mathrm{~mm}$ vs. $6.00 \mathrm{~mm}$
}

\author{
Mohammad Miraftab ${ }^{1}$, Hassan Hashemi ${ }^{1 *}$, Mohammadreza Aghamirsalim² ${ }^{2}$ Shiva Fayyaz ${ }^{1}$ and Soheila Asgari ${ }^{1}$
}

\begin{abstract}
Background: The refractive surgeries induce corneal higher order aberrations (C-HOAs). In this study, change of CHOAs after small-incision lenticule extraction (SMILE) compared to femtosecond assisted laser in situ keratomileusis (femto-LASIK), and to photorefractive keratectomy with mitomycin-C (PRK) under photopic and mesopic conditions.

Methods: In this prospective study, age, gender, and apical corneal thickness (ACT) matched cases with moderate myopia [spherical equivalent (SE) 3.00 to 6.00D) to high myopia (SE > 6.00D)] were enrolled. In addition to visual acuity and refraction, total $\mathrm{C}-\mathrm{HOA}$, coma, spherical aberration (SA), and trefoil in the 3- and 6-mm zones were measured before and 3 and 6 months after surgery.

Results: Overall, 372 moderate myopia cases (124 eyes of 124 individuals in each surgical group) and 171 high myopia cases (57 eyes of 57 individuals in each surgical group) were enrolled. At baseline, the differences in age, gender, ACT, uncorrected and corrected visual acuity, and SE were not statistically significant between subgroups of surgical methods within each myopia group (all $P>0.05$ ). At 12 months, in the moderate myopia group, there was less increase in 6-mm zone total C-HOA, coma, and SA with SMILE compared to the other groups (all $P<0.05)$. In the high myopia group, there was greater increase in photopic total $\mathrm{C}-\mathrm{HOA}$ and trefoil and less increase in mesopic SA with SMILE (all $P<0.05$ ).
\end{abstract}

Conclusions: In correction of moderate myopia, SMILE has better results in mesopic condition. In high myopia correction, femto-LASIK and PRK have better results in photopic and SMILE in mesopic condition.

Keywords: SMILE, femto-LASIK, PRK, corneal higher order aberrations, dilated pupil, non-dilated pupil

\footnotetext{
* Correspondence: research@norc.ac.ir

${ }^{1}$ Noor Ophthalmology Research Center, Noor Eye Hospital, No. 96 Esfandiar Blvd., Vali'asr Ave, Tehran, Iran

Full list of author information is available at the end of the article
}

(c) The Author(s). 2021 Open Access This article is licensed under a Creative Commons Attribution 4.0 International License, which permits use, sharing, adaptation, distribution and reproduction in any medium or format, as long as you give appropriate credit to the original author(s) and the source, provide a link to the Creative Commons licence, and indicate if changes were made. The images or other third party material in this article are included in the article's Creative Commons licence, unless indicated otherwise in a credit line to the material. If material is not included in the article's Creative Commons licence and your intended use is not permitted by statutory regulation or exceeds the permitted use, you will need to obtain permission directly from the copyright holder. To view a copy of this licence, visit http://creativecommons.org/licenses/by/4.0/. The Creative Commons Public Domain Dedication waiver (http://creativecommons.org/publicdomain/zero/1.0/) applies to the data made available in this article, unless otherwise stated in a credit line to the data. 


\section{Background}

Small-incision lenticule extraction (SMILE) which is a flapless procedure for the correction of myopia was first introduced in 2008 [1]. To date, several studies have shown its visual and refractive outcomes individually or in comparison with laser in situ keratomileusis (LASIK). A systematic review and meta-analysis [2], in which 11 out of 102 published articles comparing the two methods were reviewed, showed that the 3 to 6 month outcomes with the two procedures are not different in terms of spherical equivalent (SE), gain and loss of corrected distance visual acuity (CDVA), or predictability, and they are similar in terms of safety and efficacy.

With regard to postoperative visual quality and aberrations, studies suggest SMILE to be superior or equal to LASIK [3, 4] and inferior to wave-front guided LASIK [5]. Comparison of SMILE with laser-assisted subepithelial keratectomy (LASEK) for mild myopia $(\mathrm{SE}<3.0 \mathrm{D})$ suggested SMILE to be the preferred method due to less induced aberrations and better patient satisfaction [6]. However, in these studies, aberrations were not compared under photopic and mesopic conditions. This is while aberrations vary by pupil size [7] and should be considered for a more accurate comparison.

The aim of the present study was compare corneal higher order aberrations (C-HOA) in the 3 and $6 \mathrm{~mm}$ zones induced by SMILE compared to two conventional refractive surgical methods (femtosecond-assisted LASI K/ femto-LASIK and photorefractive keratectomy with mitomycin C/ PRK) in moderate and high myopia using a matched design.

\section{Materials and methods}

This prospective cohort study was performed on myopic patients undergoing refractive surgery at Noor Eye Hospital in Tehran, Iran in 2020. Myopia was defined based on manifest refractive spherical equivalent less or equal - 0.5 diopter (D). The moderate myopia was considered as spherical equivalent (SE) 3.00 to $6.00 \mathrm{D}$ with refractive astigmatism $<2.0 \mathrm{D}$ and high myopia $\mathrm{SE}>6.00 \mathrm{D}$ with refractive astigmatism $<2.0 \mathrm{D}$. Patients were recruited from myopic cases undergoing refractive surgery. Eligibility criteria for surgery were based on age ( $\geq 20$ years), no sign of ectasia, stable refraction in the past 12 months (a change of $\pm 0.50 \mathrm{D}$ or less), and residual stromal bed (RSB) thickness RSB + cap $>400 \mu \mathrm{m}$ for SMILE, not including the epithelium RSB $>300 \mu \mathrm{m}$ for femto-LASIK, and $\geq 350 \mu \mathrm{m}$ for PRK). All patients had been advised to stop wearing contact lenses for at least 4 weeks prior to surgery. Inclusion criteria of this study were myopia of 3.0 D or more, refractive astigmatism of $2.0 \mathrm{D}$ or less, and no corneal surgical history. Patients undergoing SMILE were enrolled consecutively For each case in the SMILE subgroup, one case from those undergoing
femto-LASIK was matched. This individual matching was repeated between SMILE and PRK cases.

\section{Matching}

Only one eye per individual was enrolled. If both eyes were in the same myopia group, one eye was randomly selected and if not, the high myopic eye was selected because of the smaller sample size. Patients in each moderate and high myopia groups were matched in terms of age, gender, and corneal thickness. Matching was based on a range of \pm 3.0 years for age and $\pm 5.0 \mu \mathrm{m}$ for corneal thickness.

\section{Ethical considerations}

This protocol of this study was reviewed and approved by the Ethics Committee of Tehran University of Medical Sciences (ID: IR.TUMS.MEDICINE.REC.1399.193). Written informed consent was obtained from patients to participate in the study. The study adhered to the tenets of the Helsinki Declaration at all stages.

\section{Surgical techniques \\ SMILE}

SMILE was performed using the VisuMax laser platform (Carl Zeiss Meditec AG, Jena, Germany). After topical anesthesia, patients were asked to fix their gaze on an internal light source. First, the posterior surface of the lenticule was cut from the periphery to the center, and then the anterior surface was cut from the center to the periphery. The parameters for lenticule creation were: cap thickness $=120 \mu \mathrm{m}$, cap diameter $=7.7 \mathrm{~mm}$, incision angle $=$ 52 , incision width $=3.0 \mathrm{~mm}$, optical zone $=6.5 \mathrm{~mm}$, and transition zone $=0.1 \mathrm{~mm}$ for cases of moderate myopia, and cap thickness $=120 \mu \mathrm{m}$, cap diameter $=7.2 \mathrm{~mm}$, incision angle $=52$, incision width $=3.0 \mathrm{~mm}$, optical zone $=$ $6.0 \mathrm{~mm}$, transition zone $=0.1 \mathrm{~mm}$ for high myopia. The postoperative treatment regimen included chloramphenicol eye drop $0.5 \%$ (Sina Darou, Tehran, Iran) every $6 \mathrm{~h}$ for 3 days, betamethasone eye drop $0.1 \%$ (Sina Darou, Tehran, Iran) every $6 \mathrm{~h}$ for 1 week, and preservative free artificial tears (Hypromellose) every $6 \mathrm{~h}$ for 1 month.

\section{Femto-LASIK}

For Femto-LASIK, after inducing topical anesthesia, first a $110 \mu \mathrm{m}$ thick flap was created using Femto LDV (Ziemer Ophthalmic Systems AG, Port, Switzerland). Then the flap was lifted, and wave-front optimized ablation was performed using WaveLight Allegretto EX500 (Alcon, Fort Worth, TX, US) in the $6.50 \mathrm{~mm}$ optical zone for moderate myopia and $6.00 \mathrm{~mm}$ for high myopia patients with a blend zone of $1.25 \mathrm{~mm}$. The postoperative treatment regimen included chloramphenicol $0.5 \%$ every $6 \mathrm{~h}$ for 3 days and betamethasone $0.1 \%$ every $6 \mathrm{~h}$ for 7 days. 
PRK

For PRK, first the corneal epithelium was mechanically scraped without alcohol. Then the WaveLight Allegretto EX500 (Alcon, TX, US) excimer laser was used to freeaberration ablate the $6.50 \mathrm{~mm}$ optical zone for moderate myopia and the $6.00 \mathrm{~mm}$ optical zone for high myopia with a $1.25 \mathrm{~mm}$ blend zone. After laser treatment, a sponge soaked in $0.02 \%$ Mitomycin-C was applied to the ablated stroma for $10 \mathrm{~s}$ per corrected diopter. After rinsing with $30 \mathrm{cc}$ sterile balanced salt solution, a bandage contact lens (Ciba vision, Duluth, GA) was applied. The postoperative treatment regimen included betamethasone $0.1 \%$ four times a day, levofloxacin eye drop $5 \mathrm{mg} / \mathrm{ml}$ four times a day, and artificial tears as needed. Daily examinations continued until observation of complete epithelial healing. The bandage contact lens was removed upon reepithelialization, and levofloxacin was discontinued; betamethasone and artificial tears were continued for another 2 weeks, after which fluorometholone $0.1 \%$ drops (Sina Darou, Tehran, Iran) was prescribed to be tapered over a course of 3 months.

\section{Pre- and post-operative examinations}

Total C-HOA, coma, spherical aberration (SA), and trefoil (3rd to 7th order) were exported in 3 and $6 \mathrm{~mm}$ zones (to simulate photopic and mesopic conditions, respectively) using Sirius (Costruzione Strumenti Oftalmici, Florence, Italy) by a single technician before and 3 and 12 months after surgery. The patient was seated in a dark room for 10-20 min to dilate the pupil at least 6 $\mathrm{mm}$; the pupil size was measured using a pupilometer (Colvard; Oasis Medical, London, UK).

In addition to $\mathrm{C}$-HOA, uncorrected and corrected distance visual acuity (UDVA and CDVA) were measured using the Snellen SC-2000 system (Nidek Inc., Tokyo, Japan), and refraction was determined using retinoscopy (ParaStop HEINE BETA 200; HEINE Optotechnik, Herrsching, Germany).

\section{Statistical analysis}

Analyses were performed using SPSS version 21 (IBM Corp., Armonk, NY, USA). Multiple generalized estimating equations (GEE) were used to examine and compare the 12-month changes in C-HOA indices between the 3 studied groups. Given the individual matched design, unstructured correlation matrix was used in correlation analysis between groups. The significant level was 0.05 . Refractive surgery safety index was calculated as postoperative CDVA / preoperative CDVA and efficacy was calculated as postoperative UDVA / preoperative CDVA.

\section{Results}

A total of 543 (372 cases with moderate myopia and 171 cases with high myopia) were enrolled into the study. All surgeries were done by two clinicians ( $\mathrm{MM}$ and $\mathrm{HH}$ ) with same experience. No complications were observed during and after the procedures. Demographic information and vision and refraction parameters in the two

Table 1 Demographic information and study parameters in moderate ( $n=372$ eyes) and high ( $n=171$ eyes) myopic patients treated with SMILE, femto-LASIK, and PRK in this study

\begin{tabular}{|c|c|c|c|c|c|c|c|}
\hline & & \multicolumn{3}{|c|}{ Moderate myopia } & \multicolumn{3}{|l|}{ High myopia } \\
\hline & & SMILE & femto-LASIK & PRK & SMILE & femto-LASIK & PRK \\
\hline \multicolumn{2}{|l|}{ Number of eyes } & 124 & 124 & 124 & 57 & 57 & 57 \\
\hline \multicolumn{2}{|l|}{ Age (years) } & $28.02 \pm 5.22$ & $28.21 \pm 4.71$ & $28.31 \pm 6.32$ & $27.76 \pm 6.39$ & $30.29 \pm 7.63$ & $28.79 \pm 7.00$ \\
\hline \multicolumn{2}{|l|}{$\operatorname{Sex}(F)$} & $66.1 \%$ & $62.9 \%$ & $64.5 \%$ & $61.8 \%$ & $58.8 \%$ & $63.6 \%$ \\
\hline \multicolumn{2}{|l|}{$\mathrm{ACT}(\mu \mathrm{m})$} & $561.08 \pm 25.88$ & $561.03 \pm 25.88$ & $560.73 \pm 25.87$ & $544.56 \pm 17.26$ & $551.00 \pm 16.50$ & $543.62 \pm 18.66$ \\
\hline \multicolumn{2}{|c|}{ Removal tissue thickness ( $\mu \mathrm{m})$} & $106.63 \pm 13.51$ & $76.43 \pm 13.79$ & $73.41 \pm 13.61$ & $143.53 \pm 16.28$ & $112.33 \pm 11.63$ & $112.56 \pm 12.38$ \\
\hline \multirow[t]{2}{*}{ MRSE (D) } & Pre-op & $-4.66 \pm 0.85$ & $-4.47 \pm 0.82$ & $-4.36 \pm 0.72$ & $-7.54 \pm 0.92$ & $-7.19 \pm 0.61$ & $-7.79 \pm 1.37$ \\
\hline & After $12 \mathrm{M}$ & $0.15 \pm 0.34$ & $-0.00 \pm 0.33$ & $0.10 \pm 0.35$ & $-0.05 \pm 0.47$ & $-0.31 \pm 0.28$ & $-0.27 \pm 0.58$ \\
\hline \multirow[t]{2}{*}{ Astigmatism (D) } & Pre-op & $-1.00 \pm 0.80$ & $-0.80 \pm 0.58$ & $-0.93 \pm 0.71$ & $-1.64 \pm 1.15$ & $-1.56 \pm 1.41$ & $-1.51 \pm 0.91$ \\
\hline & After $12 \mathrm{M}$ & $-0.40 \pm 0.40$ & $-0.39 \pm 0.29$ & $-0.45 \pm 0.29$ & $-0.57 \pm 0.53$ & $-0.50 \pm 0.05$ & $-0.37 \pm 0.20$ \\
\hline \multirow[t]{2}{*}{ UDVA (logMAR) } & Pre-op & $1.40 \pm 0.26$ & $1.37 \pm 0.28$ & $1.40 \pm 0.14$ & $1.75 \pm 0.15$ & $1.62 \pm 0.33$ & $1.73 \pm 0.21$ \\
\hline & After $12 \mathrm{M}$ & $0.01 \pm 0.03$ & $0.00 \pm 0.00$ & $0.00 \pm 0.02$ & $0.01 \pm 0.03$ & $0.02 \pm 0.06$ & $0.05 \pm 0.13$ \\
\hline \multirow[t]{2}{*}{ CDVA (logMAR) } & Pre-op & $0.00 \pm 0.00$ & $0.00 \pm 0.00$ & $0.00 \pm 0.00$ & $0.01 \pm 0.03$ & $0.00 \pm 0.00$ & $0.02 \pm 0.04$ \\
\hline & After $12 \mathrm{M}$ & $0.00 \pm 0.01$ & $0.00 \pm 0.00$ & $0.00 \pm 0.00$ & $0.00 \pm 0.00$ & $0.01 \pm 0.02$ & $0.01 \pm 0.02$ \\
\hline \multicolumn{2}{|l|}{ Safety index } & $0.99 \pm 0.03$ & $1.00 \pm 0.00$ & $1.00 \pm 0.00$ & $1.04 \pm 0.07$ & $0.98 \pm 0.04$ & $1.04 \pm 0.07$ \\
\hline \multicolumn{2}{|l|}{ Efficacy index } & $0.99 \pm 0.02$ & $1.00 \pm 0.00$ & $1.00 \pm 0.00$ & $1.04 \pm 0.07$ & $0.98 \pm 0.04$ & $1.04 \pm 0.07$ \\
\hline
\end{tabular}

SMILE small incision lenticule extraction, femto-LASIK femtosecond-assisted laser in-situ keratomileusis, PRK photorefractive keratectomy with mitomycin-C, $A C T$ apical corneal thickness, MRSE manifest refraction spherical equivalent, UDVA uncorrected distance visual acuity, CDVA corrected distance visual acuity Removal tissue thickness: maximum lenticule thickness in SMILE and ablation depth in femto-LASIK and PRK 
myopia groups are summarized in Table 1 for SMILE, femto-LASIK, and PRK subgroups. Within each myopia group, the differences between the surgical subgroups were not significant in terms of the parameters listed in Table 1 (all $P>0.05$ ), except the difference between maximum lenticule thickness in SMILE and ablation depths in femto-LASIK $(P<0.001)$ and PRK $(P<0.001)$ procedures.

\section{Total C-HOA}

Figure 1 shows one-year change in total $\mathrm{C}-\mathrm{HOA}$ in the study groups. In moderate myopia group, total C-HOA increased in all 3 subgroups in photopic and mesopic conditions (all $P<0.05$ ). The increase in $6 \mathrm{~mm}$ total $C$ HOA after SMILE was lower than femto-LASIK $(0.16 \pm$ 0.32 vs. $0.38 \pm 0.36 \mu \mathrm{m}, P<0.001)$ and PRK $(0.33 \pm$ $0.25 \mu \mathrm{m}, P=0.001)$. But the changes in $3 \mathrm{~mm}$ total $\mathrm{C}$ HOA were not significant between SMILE and femtoLASIK $(P=0.098)$ and SMILE and PRK $(P=0.184)$.

In high myopia group, the significant increase in $6 \mathrm{~mm}$ total C-HOA was not different between SMILE and femto-LASIK $(P=0.234)$ and PRK $(P=0.079)$. But increase in $3 \mathrm{~mm}$ C-HOA after SMILE $(0.21 \pm 0.24 \mu \mathrm{m})$ was higher than femto-LASIK $(0.13 \pm 0.17 \mu \mathrm{m}, P<0.001)$ and PRK $(0.19 \pm 0.15 \mu \mathrm{m} P=0.004)$.

\section{Coma}

In the moderate myopia group, $6 \mathrm{~mm}$ coma increased in the surgical subgroups. The increase with SMILE was less than the femto-LASIK $(P=0.012)$ and PRK $(P=$ 0.021 ). But in $3 \mathrm{~mm}$ zone, there was no difference between SMILE and two the other procedures (both $P>$ 0.05 ) (Table 2). In the high myopia group, $3 \mathrm{~mm}$ and $6 \mathrm{~mm}$ coma increased in three surgical subgroups, but the differences between SMILE and the other subgroups were not significant (all $P>0.05$ ) (Table 3 ).

\section{Spherical aberration}

In the moderate myopia group, the significant increase of SA with SMILE was less than the femto-LASIK $(P<$ $0.001)$ and PRK $(P<0.001)$ only in $6 \mathrm{~mm}$ zone (Table 2$)$. In the high myopia groups, similar to the moderate myopia, $6 \mathrm{~mm}$ coma was increased with all surgical procedures. But SMILE was associated with lesser increase compared to the other procedures (all $P<0.05$ ). The increase of $3 \mathrm{~mm}$ coma was not different between SMILE and the other two procedures (both $P>0.05$ ) (Table 3).

\section{Trefoil}

In the moderate myopia group, within and between change in $6 \mathrm{~mm}$ trefoil was not different with three procedures (all $P>0.05$ ) (Table 2). In the high myopia group, despite of significant increase of $6 \mathrm{~mm}$ trefoil with PRK, the difference between SMILE and PRK $(P=0.426)$ was not significant. The increase in $3 \mathrm{~mm}$ trefoil with SMILE was less than the femto-LASIK $(P<0.001)$ and PRK $(P=0.006)$ (Table 3$)$.

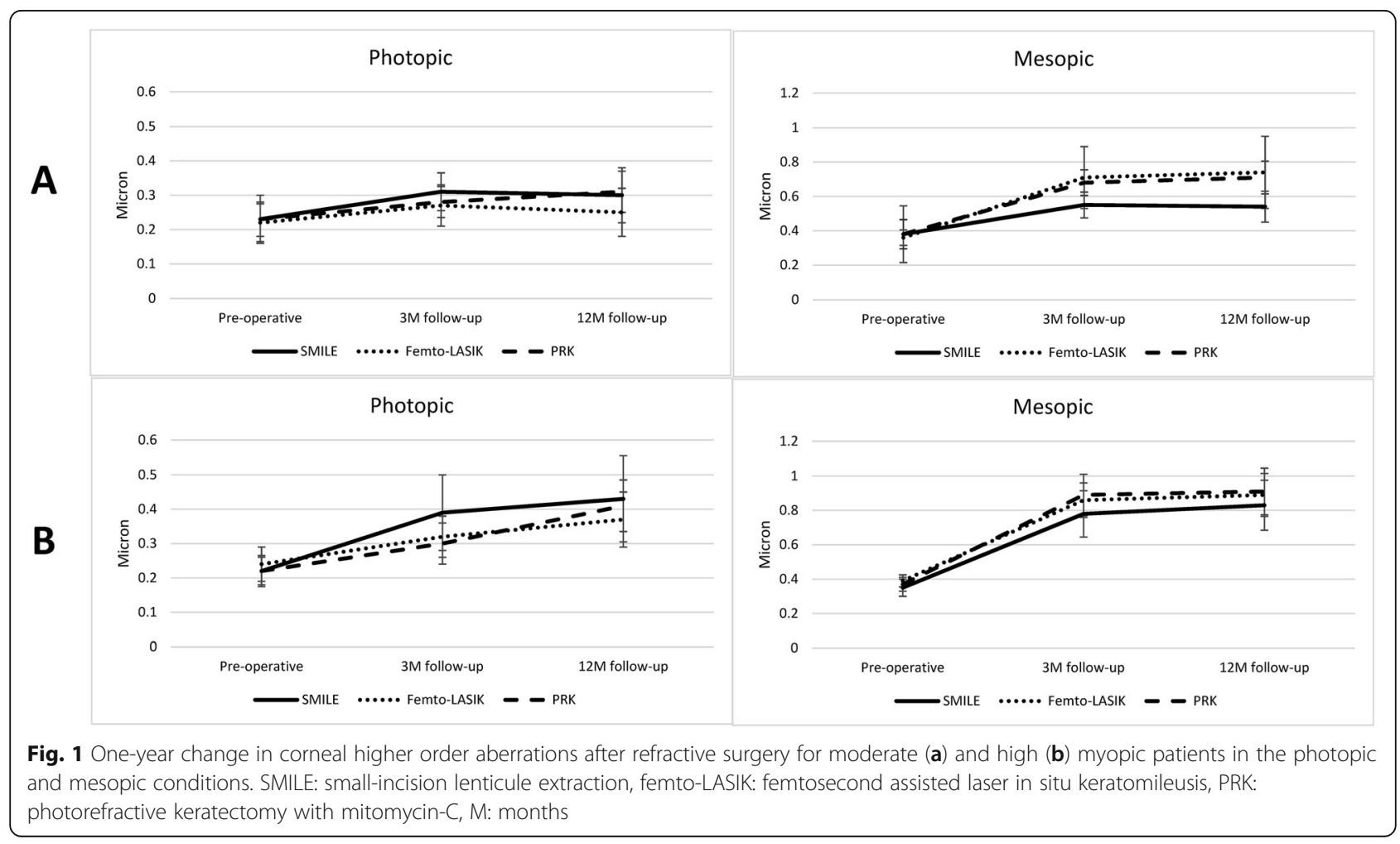


Table 2 Baseline and postoperative $3 \mathrm{~mm}$ and $6 \mathrm{~mm}$ higher order aberrations in cases of moderate myopia treated with SMILE, femto-LASIK, and PRK

\begin{tabular}{|c|c|c|c|c|c|c|c|}
\hline Index & Pupil diameter & Surgical method & Pre-operative & $3 \mathrm{M}$ follow-up & $12 \mathrm{M}$ follow-up & One-year change & $P$-value \\
\hline \multirow[t]{6}{*}{ Total coma $(\mu \mathrm{m})$} & \multirow[t]{3}{*}{ 6-mm } & SMILE & $0.22 \pm 0.21$ & $0.36 \pm 0.16$ & $0.38 \pm 0.18$ & $0.16 \pm 0.23^{a}$ & \multirow{3}{*}{$\begin{array}{l}0.012^{b} \\
0.021^{c}\end{array}$} \\
\hline & & Femto-LASIK & $0.21 \pm 0.09$ & $0.41 \pm 0.23$ & $0.46 \pm 0.31$ & $0.25 \pm 0.23^{\mathrm{a}}$ & \\
\hline & & PRK & $0.24 \pm 0.17$ & $0.45 \pm 0.18$ & $0.48 \pm 0.20$ & $0.24 \pm 0.24^{\mathrm{a}}$ & \\
\hline & \multirow[t]{3}{*}{$3-\mathrm{mm}$} & SMILE & $0.11 \pm 0.10$ & $0.14 \pm 0.08$ & $0.15 \pm 0.11$ & $0.04 \pm 0.12$ & \multirow{3}{*}{$\begin{array}{l}0.313^{b} \\
0.791^{c}\end{array}$} \\
\hline & & Femto-LASIK & $0.17 \pm 0.62$ & $0.14 \pm 0.11$ & $0.16 \pm 0.15$ & $-0.01 \pm 0.64$ & \\
\hline & & PRK & $0.11 \pm 0.08$ & $0.14 \pm 0.09$ & $0.14 \pm 0.13$ & $0.03 \pm 0.11$ & \\
\hline \multirow[t]{6}{*}{ Total SA $(\mu \mathrm{m})$} & \multirow[t]{3}{*}{$6-\mathrm{mm}$} & SMILE & $0.21 \pm 0.04$ & $0.30 \pm 0.10$ & $0.33 \pm 0.12$ & $0.11 \pm 0.09^{\mathrm{a}}$ & \multirow{3}{*}{$\begin{array}{l}<0.001^{a} \\
<0.001^{c}\end{array}$} \\
\hline & & Femto-LASIK & $0.21 \pm 0.05$ & $0.42 \pm 0.10$ & $0.45 \pm 0.10$ & $0.24 \pm 0.10^{\mathrm{a}}$ & \\
\hline & & PRK & $0.22 \pm 0.07$ & $0.43 \pm 0.12$ & $0.48 \pm 0.11$ & $0.26 \pm 0.13^{\mathrm{a}}$ & \\
\hline & \multirow[t]{3}{*}{$3-\mathrm{mm}$} & SMILE & $0.07 \pm 0.03$ & $0.07 \pm 0.04$ & $0.06 \pm 0.03$ & $-0.01 \pm 0.04$ & \multirow{3}{*}{$\begin{array}{l}0.125^{b} \\
0.482^{c}\end{array}$} \\
\hline & & Femto-LASIK & $0.06 \pm 0.02$ & $0.07 \pm 0.03$ & $0.07 \pm 0.04$ & $0.01 \pm 0.03$ & \\
\hline & & PRK & $0.07 \pm 0.03$ & $0.07 \pm 0.04$ & $0.08 \pm 0.03$ & $0.01 \pm 0.04$ & \\
\hline \multirow[t]{6}{*}{ Total trefoil $(\mu \mathrm{m})$} & \multirow[t]{3}{*}{$6-\mathrm{mm}$} & SMILE & $0.14 \pm 0.19$ & $0.14 \pm 0.07$ & $0.13 \pm 0.05$ & $-0.01 \pm 0.17$ & \multirow{3}{*}{$\begin{array}{l}0.198^{b} \\
0.271^{c}\end{array}$} \\
\hline & & Femto-LASIK & $0.14 \pm 0.06$ & $0.18 \pm 0.19$ & $0.16 \pm 0.15$ & $0.02 \pm 0.19$ & \\
\hline & & PRK & $0.14 \pm 0.08$ & $0.16 \pm 0.08$ & $0.15 \pm 0.05$ & $0.01 \pm 0.11$ & \\
\hline & \multirow[t]{3}{*}{$3-\mathrm{mm}$} & SMILE & $0.12 \pm 0.09$ & $0.16 \pm 0.08$ & $0.14 \pm 0.08$ & $0.02 \pm 0.12$ & \multirow{3}{*}{$\begin{array}{l}0.122^{b} \\
0.342^{c}\end{array}$} \\
\hline & & Femto-LASIK & $0.13 \pm 0.09$ & $0.14 \pm 0.08$ & $0.13 \pm 0.12$ & $0.00 \pm 0.11$ & \\
\hline & & PRK & $0.12 \pm 0.07$ & $0.15 \pm 0.08$ & $0.14 \pm 0.10$ & $0.02 \pm 0.11$ & \\
\hline
\end{tabular}

${ }^{a}$ Within subgroup statistically significant change

${ }^{b}$ Comparison of one-year change in indices between SMILE and femto-LASIK

c Comparison of one-year change in indices between SMILE and PRK

$M$ months, SA spherical aberration, PRK photorefractive keratectomy, SMILE small incision lenticule extraction, femto-LASIK femtosecond-assisted laser

in-situ keratomileusis

\section{Discussion}

\section{Total C-HOA}

The findings of the present study in individuals with moderate myopia (3.0 to $6.0 \mathrm{D})$ and low astigmatism (< 2.0D) suggest that there is no difference between SMILE and femto-LASIK or between SMILE and PRK in terms of $\mathrm{C}-\mathrm{HOA}$ induction when assessments are done under photopic conditions (pupil diameter: $3.0 \mathrm{~mm}$ ). However, at a $6.0 \mathrm{~mm}$ pupil diameter, SMILE is associated with less HOA induction. In cases with high myopia $(>6.0 \mathrm{D})$ and low astigmatism $(<2.0 \mathrm{D})$, there is greater increase in total $\mathrm{C}-\mathrm{HOA}$ at $3.0 \mathrm{~mm}$ pupil diameter due to induced trefoil with SMILE than with the other two methods. But at a $6.0 \mathrm{~mm}$ pupil diameter, there is less SA induction with SMILE than the other two procedures. These results were stabled after 3-month follow-up.

\section{Coma}

Induced coma after surgical procedures can be due to various factors. In SMILE, femto-LASIK, and PRKMMC, coma can be decentration-induced or develop as a result of asymmetric or irregular wound healing [811]. Also, induced coma with SMILE may be due to lack of iris registration [12]. In our study, SMILE induced very small amount of photopic pupil coma $(0.04 \pm$ $0.12 \mu \mathrm{m})$ in patients with moderate myopia and results were comparable to the other procedures. But under mesopic conditions $(6.0 \mathrm{~mm}$ pupil), there was less coma induced with SMILE which could be due to better centration in SMILE group [13], or maybe the amount of decentration with femto-LASIK and PRK has small impact on visual quality under photopic conditions. But, Yildirim et al. [14] reported no difference between SMILE and aberration-free PRK in terms of induced coma for correction mild and moderate myopia. This difference could be related to severity of myopia. As the pupil dilates and aberrations increase in mesopic conditions, outcomes achieved with SMILE appear to be superior to the other two procedures.

In our high myopic cases, compared to the moderate myopia group, the amount of induced coma was greater with all three approaches. Even in the presence of an eye tracker in excimer laser assisted procedures, the longer procedure time needed for higher correction can contribute to fixation fatigue and decentration-induced aberrations $[8,9,12]$. Regardless of the degree of myopia and pupil size, the amount of coma induced by SMILE was equal to or less than that by the other two methods. 
Table 3 Baseline and postoperative $3 \mathrm{~mm}$ and $6 \mathrm{~mm}$ higher order aberrations in cases of high myopia treated with SMILE, femtoLASIK, and PRK

\begin{tabular}{|c|c|c|c|c|c|c|c|}
\hline Index & Pupil diameter & Surgical method & Pre-operative & $3 \mathrm{M}$ follow-up & $12 \mathrm{M}$ follow-up & One-year change & $P$-value \\
\hline \multirow[t]{6}{*}{ Total coma $(\mu \mathrm{m})$} & \multirow[t]{3}{*}{ 6-mm } & SMILE & $0.20 \pm 0.09$ & $0.52 \pm 0.27$ & $0.56 \pm 0.28$ & $0.36 \pm 0.28^{a}$ & \multirow{3}{*}{$\begin{array}{l}0.535^{b} \\
0.289^{c}\end{array}$} \\
\hline & & Femto-LASIK & $0.21 \pm 0.09$ & $0.50 \pm 0.22$ & $0.54 \pm 0.22$ & $0.33 \pm 0.19^{a}$ & \\
\hline & & PRK & $0.21 \pm 0.10$ & $0.48 \pm 0.24$ & $0.52 \pm 0.26$ & $0.31 \pm 0.24^{\mathrm{a}}$ & \\
\hline & \multirow[t]{3}{*}{$3-m m$} & SMILE & $0.09 \pm 0.06$ & $0.14 \pm 0.11$ & $0.16 \pm 0.12$ & $0.05 \pm 0.11^{\mathrm{a}}$ & \multirow{3}{*}{$\begin{array}{l}0.233^{b} \\
0.823^{c}\end{array}$} \\
\hline & & Femto-LASIK & $0.10 \pm 0.07$ & $0.16 \pm 0.06$ & $0.16 \pm 0.09$ & $0.06 \pm 0.08^{\mathrm{a}}$ & \\
\hline & & PRK & $0.09 \pm 0.05$ & $0.13 \pm 0.08$ & $0.14 \pm 0.10$ & $0.05 \pm 0.10^{\mathrm{a}}$ & \\
\hline \multirow[t]{6}{*}{ Total SA $(\mu \mathrm{m})$} & \multirow[t]{3}{*}{ 6-mm } & SMILE & $0.21 \pm 0.07$ & $0.46 \pm 0.15$ & $0.45 \pm 0.15$ & $0.24 \pm 0.14^{\mathrm{a}}$ & \multirow{3}{*}{$\begin{array}{l}0.006^{\mathrm{b}} \\
<0.001^{\mathrm{c}}\end{array}$} \\
\hline & & Femto-LASIK & $0.23 \pm 0.05$ & $0.56 \pm 0.12$ & $0.53 \pm 0.12$ & $0.30 \pm 0.13^{a}$ & \\
\hline & & PRK & $0.22 \pm 0.06$ & $0.61 \pm 0.21$ & $0.60 \pm 0.21$ & $0.38 \pm 0.21^{\mathrm{a}}$ & \\
\hline & \multirow[t]{3}{*}{$3-\mathrm{mm}$} & SMILE & $0.06 \pm 0.03$ & $0.06 \pm 0.03$ & $0.08 \pm 0.04$ & $0.02 \pm 0.04$ & \multirow{3}{*}{$\begin{array}{l}0.106^{b} \\
0.722^{c}\end{array}$} \\
\hline & & Femto-LASIK & $0.06 \pm 0.03$ & $0.08 \pm 0.04$ & $0.07 \pm 0.03$ & $0.01 \pm 0.04$ & \\
\hline & & PRK & $0.07 \pm 0.03$ & $0.06 \pm 0.05$ & $0.07 \pm 0.04$ & $-0.00 \pm 0.06$ & \\
\hline \multirow[t]{6}{*}{ Total trefoil $(\mu \mathrm{m})$} & \multirow[t]{3}{*}{$6-\mathrm{mm}$} & SMILE & $0.14 \pm 0.07$ & $0.16 \pm 0.08$ & $0.17 \pm 0.08$ & $0.03 \pm 0.09$ & \multirow{3}{*}{$\begin{array}{l}0.426^{b} \\
0.130^{c}\end{array}$} \\
\hline & & Femto-LASIK & $0.17 \pm 0.10$ & $0.22 \pm 0.15$ & $0.21 \pm 0.16$ & $0.04 \pm 0.16$ & \\
\hline & & PRK & $0.13 \pm 0.08$ & $0.19 \pm 0.11$ & $0.18 \pm 0.10$ & $0.05 \pm 0.12^{a}$ & \\
\hline & \multirow[t]{3}{*}{$3-\mathrm{mm}$} & SMILE & $0.13 \pm 0.09$ & $0.21 \pm 0.12$ & $0.23 \pm 0.10$ & $0.10 \pm 0.15^{a}$ & \multirow{3}{*}{$\begin{array}{l}<0.001^{b} \\
0.006^{c}\end{array}$} \\
\hline & & Femto-LASIK & $0.15 \pm 0.09$ & $0.16 \pm 0.11$ & $0.18 \pm 0.13$ & $0.03 \pm 0.14$ & \\
\hline & & PRK & $0.13 \pm 0.09$ & $0.16 \pm 0.09$ & $0.15 \pm 0.11$ & $0.02 \pm 0.14$ & \\
\hline
\end{tabular}

\footnotetext{
${ }^{a}$ Within sub-group statistically significant change

${ }^{b}$ Comparison of one-year change in indices between SMILE and femto-LASIK

c Comparison of one-year change in indices between SMILEand PRK

$M$ months, SA spherical aberration, PRK photorefractive keratectomy, SMILE small incision lenticule extraction, femto-LASIK femtosecond-assisted laser in-situ keratomileusis
}

Similarly, in the study by Yang et al. [15], induced coma in the myopic SMILE group $(0.22 \mu \mathrm{m})$ was not significantly different from the femto-LASIK group $(0.13 \mu \mathrm{m})$.

\section{Spherical aberration}

In refractive surgery, the shape of the cornea is changed from prolate to oblate. The greater the degree of correction and ablation depth, the greater the corneal aspheric change and the greater the SA. Therefore, the amount of induced SA in the high myopia group was significantly higher than the moderate myopia group. The amount of $3.0 \mathrm{~mm}$ SA induced by the three procedures was not significantly different. However, regardless of the degree of myopia, there was less $6.0 \mathrm{~mm}$ SA induction with SMIL E. This could be attributed to the fact that the integrity of the anterior corneal layers is better preserved with SMILE. Some studies showed that vertical side cut of corneal lamellae during flap creation in LASIK lead to loss of corneal stiffness and mid peripheral corneal bulging which increase SA [16]. Also, the larger functional optical zone after SMILE was associated with smaller corneal asphericity (more prolate) and may have a contribution to lower SA [17].

\section{Trefoil}

In our high myopia group, SMILE showed greater $3.00 \mathrm{~mm}$ trefoil induction compared to femto-LASIK and PRK. However, there were no significant differences in the $6 \mathrm{~mm}$ pupil. This could be due to micro-distortion of the corneal center in the correction of high myopia [18]. In the sample of our study, trefoil increased by $0.10 \mu \mathrm{m}$ after 12 months and in the study by Yildirim et al. [19] increased by $0.02 \mu \mathrm{m}$ one year after surgery. Since trefoil impacts the retinal image quality less than other HOA, these observations may be of little clinical value.

In choosing the best surgical method, in addition to eligibility criteria, the patient's occupation and lifestyle should be considered. Aberrations vary by pupil size which depends on incoming light and working distance [20]. In tasks such as driving at night, maintaining mesopic vision quality is more important, and therefore SMILE can be recommended. In near work, such as surgery, maintaining quality of vision under photopic conditions should be the priority, and thus, femto-LASIK or PRK are recommended.

\section{Conclusions}

As a limitation of the present study, it was not possible to apply random allocation to the three surgical methods 
due to the patient eligibility criteria of each method. However, since we applied multiple matching, we can conclude that in cases with moderate myopia and low astigmatism, SMILE is preferred to femto-LASIK and PRK because of less induction of HOAs in low light conditions. In cases of high myopia and low astigmatism, femto-LASIK and PRK offer better daylight results while SMILE offers better outcomes in low light conditions. In other words, the choice of surgical method will should be based on the patient's condition.

\section{Abbreviations}

SMILE: Small-incision lenticule extraction; femto-LASIK: Femtosecond-assisted laser in situ keratomileusis; PRK: Photorefractive keratectomy with mitomycin C; CDVA: Corrected distance visual acuity; UDVA: Un corrected distance visual acuity; C-HOA: Corneal higher order aberrations; SE: Spherical equivalent; RSB: Residual stromal bed; SA: Spherical aberration; GEE: Generalized estimating equations

\section{Acknowledgements}

Not applicable.

\section{Authors' contributions}

Concept and design (MM and $\mathrm{HH})$, Data acquisition (MM and $\mathrm{HH})$, Data interpretation (MA and SA), Drafting manuscript (SA and SF), critical revision (MM, HH, MA), final approve (All authors)

\section{Funding}

None.

\section{Availability of data and materials}

The data will be available in case of reasonable request by corresponding author.

\section{Declarations}

\section{Ethics approval and consent to participate}

The study was approved by the Ethics Committee of Tehran University of Medical Sciences (ID: IR.TUMS.MEDICINE.REC.1399.193). The study adhered to the tenets of the Helsinki Declaration at all stages. Written informed consent was obtained from patients to participate in the study. The study adhered to the tenets of the Helsinki Declaration at all stages.

\section{Consent for publication}

Not applicable.

\section{Competing interests}

The authors declare that they have no competing interests.

\section{Author details}

'Noor Ophthalmology Research Center, Noor Eye Hospital, No. 96 Esfandiar Blvd., Vali'asr Ave, Tehran, Iran. ${ }^{2}$ Translational Ophthalmology Research Center, Tehran University of Medical Sciences, Tehran, Iran.

Received: 17 February 2021 Accepted: 10 May 2021

Published online: 15 May 2021

\section{References}

1. Sekundo W, Kunert K, Russmann C, Gille A, Bissmann W, Stobrawa G, et al. First efficacy and safety study of femtosecond lenticule extraction for the correction of myopia: six-month results. J Cataract Refract Surg. 2008;34: 1513-20.

2. Zhang Y, Shen Q, Jia Y, Zhou D, Zhou J. Clinical Outcomes of SMILE and FSLASIK used to treat Myopia: AmMeta-analysis. J Refract Surg. 2016;32:256-65.

3. Lin F, XU Y, Yang Y. Comparison of the visual results after SMILE and femtosecond laser-assisted LASIK for myopia. J Refract Surg. 2014;30:248-54.
4. Ganesh S, Gupta R. Comparison of visual and refractive outcomes following femtosecond laser- assisted lasik with smile in patients with myopia or myopic astigmatism. J Refract Surg. 2014;30:590-6.

5. Chen X, Wang Y, Zhang J, Yang SN, Li X, Zhang L. Comparison of ocular higher-order aberrations after SMILE and Wavefront-guided Femtosecond LASIK for myopia. BMC Ophthalmol. 2017;17:42.

6. Yu M, Chen M, Wang B, Zou L, Zhu X, Dai J. Comparison of visual quality after SMILE and LASEK for mild to moderate myopia. J Refract Surg. 2015;31: 795-800.

7. Oshika T, Tokunaga T, Samejima T, Miyata K, Kawana K, Kaji Y. Influence of pupil diameter on the relation between ocular higher-order aberration and contrast sensitivity after laser in situ keratomileusis. Invest Ophthalmol Vis Sci. 2006:47:1334-8.

8. Padmanabhan P, Mrochen M, Viswanathan D, Basuthkar S. Wavefront aberrations in eyes with decentered ablations. J Cataract Refract Surg. 2009; 35:695-702.

9. Guirao A, Williams DR, Cox IG. Effect of rotation and translation on the expected benefit of an ideal method to correct the eye's higher-order aberrations. J Opt Soc Am A Opt Image Sci Vis. 2001;18:1003-15.

10. Pallikaris IG, Kymionis GD, Panagopoulou SI, Siganos CS, Theodorakis MA, Pallikaris Al. Induced optical aberrations following formation of a laser in situ keratomileusis flap. J Cataract Refract Surg. 2002;28:1737-41.

11. Potgieter FJ, Roberts C, Cox IG, Mahmoud AM, Herderick EE, Roetz M, et al. Prediction of flap response. J Cataract Refract Surg. 2005;31:106-14.

12. Liu M, Chen Y, Wang D, Zhou Y, Zhang X, He J, et al. Clinical outcomes after SMILE and femtosecond laser-assisted LASIK for myopia and myopic astigmatism: a prospective randomized comparative study. Cornea. 2016;35: 210-6.

13. Wong JX, Wong EP, Htoon HM, Mehta JS. Intraoperative centration during small incision lenticule extraction (SMILE). Medicine (Baltimore). 2017:96: e6076.

14. Yildirim Y, Olcucu O, Alagoz C, Basci A, Agca A, Yasa D, et al. visual and refractive outcomes of photorefractive keratectomy and small incision lenticule extraction (SMILE) for myopia. J Refract Surg. 2016;32:604-10.

15. Yang W, Liu S, Li M, Shen Y, Zhou X. Visual Outcomes after Small Incision Lenticule Extraction and Femtosecond Laser-Assisted LASIK for High Myopia. Ophthalmic Res. 2020:63:427-33.

16. Guo H, Hosseini-Moghaddam SM, Hodge W. Corneal biomechanical properties after SMILE versus FLEX, LASIK, LASEK, or PRK: a systematic review and meta-analysis. BMC Ophthalmol. 2019; 19: 167.

17. Hou J, Wang Y, Lei Y, Zheng X. Comparison of effective optical zone after small-incision lenticule extraction and femtosecond laser-assisted laser in situ keratomileusis for myopia. J Cataract Refract Surg. 2018; 44: 1179-1185.

18. Qin B, Zhao J, Li M, Yao P, Zhou X. The comparison of visual outcomes, aberrations, and Bowman's layer micro-distortions after femtosecond laser small-incision lenticule extraction (SMILE) for the correction of high and moderate myopia and myopic astigmatism. BMC Ophthalmol. 2019;19:138.

19. Yıldırım Y, Alagöz C, Demir A, Ölçücü O, Özveren M, Ağca A, et al. long-term results of small-incision lenticule extraction in high myopia. Turk J Ophthalmol. 2016:46:200-4.

20. Koch DD, Samuelson SW, Haft EA, Merin LM. Pupillary size and responsiveness. Implications for selection of a bifocal intraocular lens. Ophthalmology. 1991;98:1030-35.

\section{Publisher's Note}

Springer Nature remains neutral with regard to jurisdictional claims in published maps and institutional affiliations.

Ready to submit your research? Choose BMC and benefit from:

- fast, convenient online submission

- thorough peer review by experienced researchers in your field

- rapid publication on acceptance

- support for research data, including large and complex data types

- gold Open Access which fosters wider collaboration and increased citations

- maximum visibility for your research: over $100 \mathrm{M}$ website views per year

At BMC, research is always in progress.

Learn more biomedcentral.com/submissions 